Journal Article

\title{
Participatory Adaptation Planning and Costing Applications in Agricultural Adaptation in Western Kenya
}

Key words: adaptation; climate change; costing; cost benefit analysis; decisionmaking; multi-stakeholder; participatory planning; smallholder agriculture.

\footnotetext{
Abrar Chaudhury* ${ }^{1,2}$, Ariella Helfgott ${ }^{1,2,3}$, Thomas F. Thornton ${ }^{1}$ and Chase Sova ${ }^{1,2}$

${ }^{1}$ Environmental Change Institute, University of Oxford, UK

${ }^{2}$ CGIAR Research Program on Climate Change, Agriculture and Food Security (CCAFS)

${ }^{3}$ School of Earth and Environmental Sciences, University of Adelaide, Australia

* Corresponding Author
}

\footnotetext{
* Abrar Chaudhury

Environmental Change Institute, University of Oxford, South Parks Road, Oxford OX1 3QY

abrarchaudhury@gmail.com and abrar.chaudhury@ouce.ox.ac.uk +(44) 7861478411
} 


\begin{abstract}
Adaptation to climate change is an important theme in the strategy and policy of institutions around the world. Billions of dollars are allocated every year, based on cost estimates of actions to cope with, or benefit from the impacts of climate change. Costing adaptation, however, is complex, involving multiple actors with differing values and a spectrum of possible adaptation strategies and pathways. Currently, expert driven, topdown approaches dominate adaptation costing in practice. These approaches are subject to misallocation, with global funds not always reaching vulnerable communities in most need. This paper introduces an analytical framework called Participatory Social Return on Investment (PSROI), which provides a structured framework for multi-stakeholder planning, selection and valuation of appropriate methods of adaptation. The broader economic, social and environmental impacts of these adaptation actions are explored and valued through a participatory process. PSROI is strength-based, building local capacity and generating stakeholder buy-in. The financial valuation generated provides an additional tool for examining and prioritizing adaptation actions based on their impact. Results from a pilot of the PSROI framework in a smallholder farming community in Western Kenya provide empirical evidence for the difference between expert driven desk-based and ground-based cost estimates that involve local communities. There was an approximate $70 \%$ reduction in the valuation of an agroforestry intervention, selected by the local community, when compared between the desk-based valuation and that of the local community, using primary field data. This reduced expectation of the deskbased PSROI is justified by coherent explanations such as lack of knowledge about the intervention, misconception about the potential costs and benefits, and the risk-averse nature of the farmers. These and other important insights are fundamental for planning and decision-making, as well as appropriate targeting and delivery of funding for adaptation.
\end{abstract}




\section{Introduction}

Adapting to climate change is costly, particularly for developing countries that rely on the resources most sensitive to climate change, such as agriculture and fishing, and that have little capacity to adapt (IPCC, 2014, Adger et al., 2003). Many developing countries cannot meet these added adaptation costs, which makes planned efforts to adapt more difficult (Stern, 2007). Yet without adaptation, development will be threatened and even reversed (World Bank, 2010a).

Global budgets for adaptation committed by developed countries, which already reaches billions of dollars, are based on estimates of the costs that vulnerable countries require to cope with the negative consequences of climate change. These cost estimates are currently dominated by remote top-down approaches (World Bank, 2010a, UNFCCC, 2007) that rarely capture the local impacts of climate change, the costs of actions needed to cope with it, or to capitalize on local strengths and opportunities. While top-down models appeal to policy-makers because of their simplicity, there is a risk that actual costs may be very different, and funds may not match the needs of target communities without feedback of appropriate local information (Parry et al., 2009). Global risk based methodologies such as the climate resilient development approach promoted by the World Bank (2010a), and the loss aversion approach developed by the Economics of Climate Change Working Group (2009) provide useful frameworks for national planners to identify and cost sectors sensitive to climate change. The top-down approach of these frameworks makes it challenging for national planners to identify local needs and prioritize scarce resources. Ostrom (2010) contends that solutions negotiated at global level do not work well if these are not translated at national, regional and local levels. 
Alongside the current global and national estimates of costing for adaptation, decision makers need reliable local costing data to bridge the gaps between the planned and actual needs of communities affected by climate change. This is a complex process that involves multiple actors at many levels, from national organizations to local communities, who may have different values and a spectrum of possible pathways for adaptation. Global and national adaptation funders and policy-makers recognize the value of incorporating input from all stakeholders (World Bank, 2010a, OECD, 2009) including local communities, but lack the appropriate tools and resources to obtain and incorporate these inputs in a timely and efficient manner.

Beyond simply generating more reliable cost estimates at the local level, economic assessments must also reflect the actual needs and potential roles of local agents or stakeholders and explore innovative ways in which they can be involved. This is the domain of participatory assessments where local stakeholders are part of the research process that leads to action. A stakeholder-focused approach to economic assessments is gaining greater attention in local level action research (Lunduka et al., 2012).

These questions on resource allocation for adaptation and the lack of a credible bottomup participatory planning and costing framework, motivated the research of this paper. The specific aims of this paper are to develop a novel bottom-up analytical and methodological framework for planning and costing of climate change adaptation from multiple perspectives. To test the framework in a participatory context within a pilot study and finally, using the pilot study to evaluate the appropriateness of the framework both locally and globally. 


\subsection{Overview of the Planning and Costing Framework}

This paper introduces a novel bottom-up planning and costing framework that we have named Participatory Social Return on Investment (PSROI). PSROI is a structured framework for multi-stakeholder planning and costing locally appropriate methods and interventions for adapting to climate change. The PSROI framework builds on Social Return on Investment (SROI), an established stakeholder centred framework for estimating and managing the economic, social and environmental outcomes of any activity or an organization (Nicholls et al., 2012, Lingane and Olsen, 2004). Developed in 2000 by the Robert Enterprise Development Fund in the US, the SROI methodology has evolved over the last decade through several iterations. This paper uses the latest version of the framework 'A Guide to Social Return on Investment' (Nicholls et al., 2012) that was published by The SROI Network. SROI is a six-step analysis process that involves reviewing the inputs, outputs, outcomes, and impacts of an intervention generated and experienced by stakeholders. Using a visual 'Impact Map', SROI tells the story of how change is being created by measuring and putting a monetary value on economic, social and environmental outcomes that are often hard to measure and are routinely left out of standard costing analysis.

Because SROI focuses on these harder to value outcomes, it encourages the use of judgement by the project planners, at many critical steps, to keep the process of analysis moving. SROI methodology is also designed to value known interventions, without the stakeholders' active participation in either identifying the problem or selecting the solution. This, according to Ackoff $(1974$, p.8), is why practitioners "fail more often because (they) solve the wrong problem than because (they) get the wrong solution to the right problem". Using SROI for planning, rather than evaluation of a known intervention, requires participants to visualize each step of the process along a timeline 
and to estimate the costs and benefits of an action that has yet to happen. This cannot be meaningfully achieved for any process that people neither understand nor own.

PSROI overcomes these limitations by requiring participation of stakeholders at each stage of the planning, decision-making, valuation and validation process. In the case of climate change adaptation, this process begins with choosing the adaptation theme, codesigning appropriate adaptation strategies and pathways that build on existing strengths and valuation of the economic, social and environmental costs and benefits over the lifetime of these actions. The participatory process that delivers this central involvement is the ' $\mathrm{P}$ ' in PSROI.

Cost estimates are unavoidably subjective and depend on what is counted and what is not, what value is then given to anything included in the analysis, and what assumptions are made about the future for the life of the intervention (Boyle, 2000). This is the reality whether global institutions, scientific organisations or local communities make the estimates. PSROI works with this inevitable subjectivity and acknowledges that every point of view adds to the costing analysis. This subjectivity is reduced by incorporating many diverse stakeholders in the process of understanding and assessing the costs and benefits of implementing any intervention, both locally and more widely. PSROI identifies and records where value is being created, who is creating it, and who benefits from it. This analytical process, which underpins PSROI, provides the participants with a much deeper understanding of the challenges and opportunities and the reality of potential costs and benefits. Addressing such challenges and opportunities before implementation can save precious time and resources for developers, policy makers and communities. It also ensures that efforts are targeted and any adaptation intervention is more effective, sustainable and ethical. 
The case study of a smallholder farming community, Kochiel Village in Western Kenya is used to demonstrate the applicability and robustness of the PSROI framework. The Kochiel case provides strong evidence that the cost estimates for a selected plan of action made by remote stakeholders and those made locally by communities who have to implement, live with and maintain the adaptation action, are fundamentally different. The PSROI framework has been subsequently applied in other smallholder agricultural communities in East and West Africa and South-East Asia to examine and prioritize adaptation activity based on multiple and varied contextualized impacts (Sumernet, 2013). This positively demonstrates the more general applicability of the framework

The paper begins with a theoretical introduction to planning and costing climate change adaptation actions, leading to the five-step PSROI framework. It continues with findings from the pilot application of PSROI in Kochiel, Western Kenya followed by discussion on the findings. The paper concludes with an assessment of the potential of PSROI as a planning and costing framework for adaptation actions to cope with climate change.

\section{Theoretical Foundations of the Planning and Costing Framework}

PSROI integrates concepts from, adaptation, development, participation and costing literature to develop an integrated framework. This section discusses these concepts in more detail and concludes with the introduction of planning and costing frameworks underpinning PSROI.

\subsection{The Concept of Adaptation}

A potential barrier to costing adaptation is how it is defined. Put simply, adaptation encompasses all actions designed to ease the negative consequences of climate change. However, attempts at formal definitions differ, revealing a lack of consensus on what 
adaptation can or should mean, which highlights the complex nature of processes involved (Smit and Pilifosova, 2003, Smithers and Smit, 1997). The Intergovernmental Panel on Climate Change (IPCC) (2007, p.76) defines adaptation as "initiatives and measures to reduce the vulnerability of natural and human systems against actual or expected climate change effects". Adaptation, from the human perspective of global change, usually refers to a process, action or outcome in a system (household, community, group, sector, region, country) in order for that system to better cope with, manage, or adjust to some changing condition, stress, hazard, risk or opportunity (Smit and Wandel, 2006). Stern (2007) applies adaptation to building resilience and recognizes that it will be a key response in reducing vulnerability to climate change. Adger et al (2003) approach adaptation from the perspective of coping with consequences of climate change while Thornton and Manasfi (2010) stress that adaptation involves continuous and intersecting processes in response to environmental change, which themselves may become drivers of socio-ecological change.

Planning adaptation initiatives requires a clear understanding of what is adapting, to what, over what time frame and what changes are acceptable or desirable to whom (Helfgott, 2011, Smith et al., 2000). The answers to these questions often differ between relevant parties and can also change during the analysis, making adaptation planning a wicked problem (Rittel and Webber, 1973). Furthermore, these answers frame the adaptation challenge and shape subsequent actions. Affected stakeholders need to participate in framing the adaptation in order to ensure that the consequent actions remain relevant. PSROI takes this integrated approach to adaptation as the core logic for the analytical design. 


\subsection{Participation}

A participatory approach to planning and costing of adaptation mitigates the inherent mismatch of top-down costing models by capturing local realities (Parry et al., 2009). Ulrich (1987) considers participatory approach to be a moral imperative and also a methodological necessity for rigorous analysis. Mikkelsen (2005) shows that interventions are likely to be more efficient, effective and sustainable, the higher the intervention sits on the ladder of participation from informing, through consulting, to community empowerment. Nyong et al. (2007) argues in favour of participation by giving examples of farmers in Africa who already have a comprehensive set of coping strategies that policymakers, and others, can draw upon to develop appropriate adaptation strategies. Granvotter (1973) promotes a network approach for generating small-scale interactions that translate into large-scale patterns, which in turn feedback into small groups.

Participatory approaches, especially rapid assessments, are however not without limitations. They are not the panacea that many assume and have their critics (Mosse, 2004, Cooke and Kothari, 2001, Nelson and Wright, 1995). Criticism focuses particularly on the technical limitations of participation, methodological weaknesses of appraisal tools, elite capture of the process and blind spots concerning where change is essential. Green (2002, p.67) warns that participation, although now a normal part of development planning and implementation, "may in practice replicate existing social divisions, be appropriated by the elite and the articulate, and exclude poorer and marginalised groups, including women". Some go as far as to dub participation "the new tyranny" (Cooke and Kothari, 2001, p.3). Rahnema (1992) characterises participatory methods simply as new and more subtle forms of manipulation. 
Our approach addresses these practical challenges by drawing upon development theory, which over the course of several decades has undergone a paradigm shift from problembased approaches, focusing on what is lacking in societies and the provision of external resources, expertise and solutions, to strength-based approaches that focus on the strengths in societies and building on these existing capacities. People are thereby empowered for their own development from the inside out (Mikkelsen, 2005). Although there are both capacities and deficiencies in every community, the foundation principle of a strength-based approaches is to focus positively on capacities, which is more likely to empower people and mobilize them to create worthwhile and sustainable change from within (Saleebey, 1996). This process enhances people's capacity to adapt and reduces the costs of change. It also implies a commitment to equity, empowering those who are marginalized, excluded or deprived (Chambers, 1994) yet allows people to discover and identify important issues such as the right to services by exercising their democratic right to participate in decision-making (Gaventa, 2004). Active examples of strengthbased approaches are abundant, from family planning schemes in Kenya, which emphasizes existing local initiatives (Appleford, 2013), to Human Immunodeficiency Virus (HIV) / Acquired Immunodeficiency Syndrome (AIDS) prevention in Nigeria that focuses on community involvement and places value on local knowledge and capacity (Iyiani et al., 2011).

PSROI employs an adaptation framework that systemically uses stakeholder norms and visions of adaptation, builds on existing strengths to prioritize and plan local adaptation initiatives. It also takes into account the technical viability of any intervention (Khwaja, 2004). A good design, according to design theory, is one that incorporates a balance of what is financially feasible, sustainable, and desired by users (Brown, 2009). In practice, this approach involves a recursive process of gathering stakeholders to negotiate the 
boundaries of the system under consideration (which subsequently affects who is a legitimate stakeholder). Stakeholders then identify relevant challenges, and decide which features of the system must be preserved, which can change and to what degree. Costs for actions needed to achieve preservation aimed for can be more reliably estimated under this approach.

\subsection{Defining Costs and the Adaptation Valuation Principle}

The literature examines several links between adaptation and development (McGray et al., 2007, IPCC, 2007, Huq and Reid, 2004, Munasinghe, 2003). Some argue that adaptation needs to be seen as an integral part of a country's development planning, because economic growth will eventually be damaged by ignoring climate change and not building adaptive measures (Chambwera and Stage, 2010, UNDP, 2007). Like development, adaptation is often approached as a purely economic problem because of the fundamental issue that the resources to be allocated are scarce (Chambwera and Stage, 2010). This leads to the difficulty of how best to prioritize different adaptation strategies, when faced with resource constraints.

The impacts of climate change can to some extent be absorbed, although there are costs associated with such actions (Stern, 2007). Such costs of action on climate change are significantly lower than costs of inaction in the future (IPCC, 2007). IPCC (2007, p.76) defines adaptation costs as "costs of planning, preparing for, facilitating and implementing adaptation measures including transaction costs". Justifying the need for simplified analysis, the World Bank (2010a, p.6) takes a full costing approach of defining adaptation costs as the "costs of development initiatives needed to restore welfare to the levels prevailing before climate change". Resources used for adaptation are considered an investment, and need to be allocated in relation to competing demands for available resources (Chambwera and Stage, 2010). This presents the stakeholders 
(national, local or household) with the decision of how much to adapt. One possibility is to adapt fully to climate change using the World Bank (2010a) approach, which may become prohibitively costly due to the extent of the impacts produced by climate change. The option of doing nothing is difficult to justify morally. A third option is to follow the development strategy of welfare maximization by investing until the marginal benefits of adaptation measures exceed the marginal costs, although this means that some residual damage will remain in the form of welfare loss not compensated for by adaptation measures. PSROI takes forward the pragmatic principles of welfare maximisation to compensate for the welfare loss from climate change.

\subsection{Costing Framework}

The design of the PSROI framework is not about proposing a new valuation technique while well-established valuation practices and methods exist such as cost benefit analysis (CBA), cost effectiveness and social accounting, but is about incorporating a participatory focus in the valuation process. PSROI uses the core costing methodology of the SROI framework (Nicholls et al., 2012) which in turn has its roots deeply embedded in traditional CBA.

In practice, costs are often immediate whilst benefits accrue over time. It is therefore necessary to adjust for the value of money over time by using an appropriate discount rate, so that flows of both benefits and costs over time are expressed on a common basis in terms of their Net Present Value (NPV). The CBA is based on the NPV principle that is represented by the following formula:

$$
\boldsymbol{N P V}=\sum_{t=0}^{n} \frac{(\text { Benfits }- \text { Costs }) t}{(1+\mathrm{r})^{t}}
$$

Where $\mathrm{r}=$ discount rate, $\mathrm{t}=$ year, $\mathrm{n}=$ analytic horizon (in years) 
The CBA is a practical way of assessing the desirability of projects where it is important to take a longer (time horizon) and wider (impacts to multiple stakeholder) view (Prest and Turvey, 1965). It is considered to be an appropriate approach when assessing specific and stable measures that are known and identifiable, but it is not without limitations. CBA often omits non-marketable values (Omura, 2004) and usually cannot include all value criteria (Oka, 2003). Furthermore, what can be considered benefits and costs may differ between stakeholders and those with power of implementation, or those in control may influence what is included and excluded. When CBA is applied to environmental issues, it may also oversimplify complex ecosystems (Hanley, 1992). Further, CBA is a static analysis based on assumptions and so will not always provide for the most effective adaptation intervention. Despite these challenges, CBA is widely used for local and national decision-making and provides an adequate point to start a discussion on adaptation priorities.

The SROI expands the traditional one-dimensional economic CBA analysis by focusing beyond the economics of an activity to capture the underlying social and environmental outcomes of the activity as well. For example, while the CBA may focus on the economic benefits generated from increased yield from drought resistant seeds, the SROI also captures other outcomes these economic benefits bring to the community, such as better health from greater income or improved nutrition. Market prices are typically used to calculate the costs and benefits of tradable goods. However, estimating the economic, social and environmental value of non-tradable and non-marketable goods is a more reflective process that requires use of financial proxies and non-monetary valuation methods. SROI assigns values to outcomes that are harder to estimate and so are routinely left out of traditional economic calculations by using non-monetary contingent valuation methods, such as willingness to pay, willingness to accept 
compensation and hedonic pricing (Malpezzi, 2008, Bateman and Willis, 2001, Mitchell and Carson, 1989)

The SROI ratio is calculated by dividing the present value of net triple line benefits by the present value of investments or input costs.

$$
\text { SROI Ratio }=\frac{\text { Present Value of Net Triple Line Benefits }}{\text { Present Value of Investments (Input Costs) }}
$$

This calculates the net monetary value of the economic, social and environmental benefits for each unit of investment (e.g. SROI of 10 means $\$ 10$ of net benefits for each $\$ 1$ of investment). For the remainder of this paper the SROI ratio is referred to as the PSROI ratio for representing the monetary valuation step in the PSROI framework. The next section introduces the methodological foundations behind the PSROI framework.

\section{Methodology}

This paper focuses on introducing the PSROI framework and its application in the field. While the results from the pilot study serve to discuss, analyse and criticise PSROI as a robust and scalable framework, it is not the scope of this paper to comment on the effectiveness or appropriateness of the specific adaptation intervention chosen by the stakeholders. The real insights from this pilot are from comparing the differences in the valuation assumptions of the local stakeholders suffering from climate change and those at a distance. These insights provide valuable feedback for improving and strengthening the design, methodology and application of the PSROI framework.

The PSROI framework was piloted in the case study site of Kochiel village in Western Kenya. The case study methodology was adopted because it offers a holistic, in-depth approach (Orum et al., 1991) and allows for data triangulation by bringing out details 
from the views of participants in relation to other sources of information (Tellis, 1997). This corresponds well with the stakeholder-centred approach of the PSROI framework. A mixed-methods approach of qualitative and quantitative analysis (Silverman, 2013) supported by direct observations is used for applying PSROI. The analysis is kept as structured as possible so that the method can serve as a template for future parallel studies (King et al., 1994). Wherever possible, triangulation is applied to many sources of information or supplementing interview data with physical observations. Specific methods, steps and assumptions for applying PSROI are presented in the next section, along with its limitations and areas of risks. Specific data on the PSROI pilot study is presented in the results section.

\section{PSROI Framework}

The PSROI framework follows a five-step process (see Figure 1). The process commences with selection of stakeholders for inclusion in the analysis, selection of an appropriate adaptation theme by the stakeholders to address the effects of climate change followed by technical design of an adaptation intervention to address the economic, social and environmental challenges identified by the stakeholders. A deskbased or baseline economic, social and environmental cost-benefit analysis is carried out using secondary and expert data, which is validated and compared with results from primary field data. The unit of measure for the intervention is flexible and may be a project, program, service, part or total operations of an organization. Collectively, these five steps produce a prioritized, appropriately planned, and costed adaptation intervention to be undertaken by the stakeholders. While the framework steps occur sequentially they nevertheless inform one another through feedback loops. The process of selection, design, measurement and validation may go through several iterations to yield a more refined and appropriate adaptation strategy. 


\section{Five Steps of PSROI Analysis}

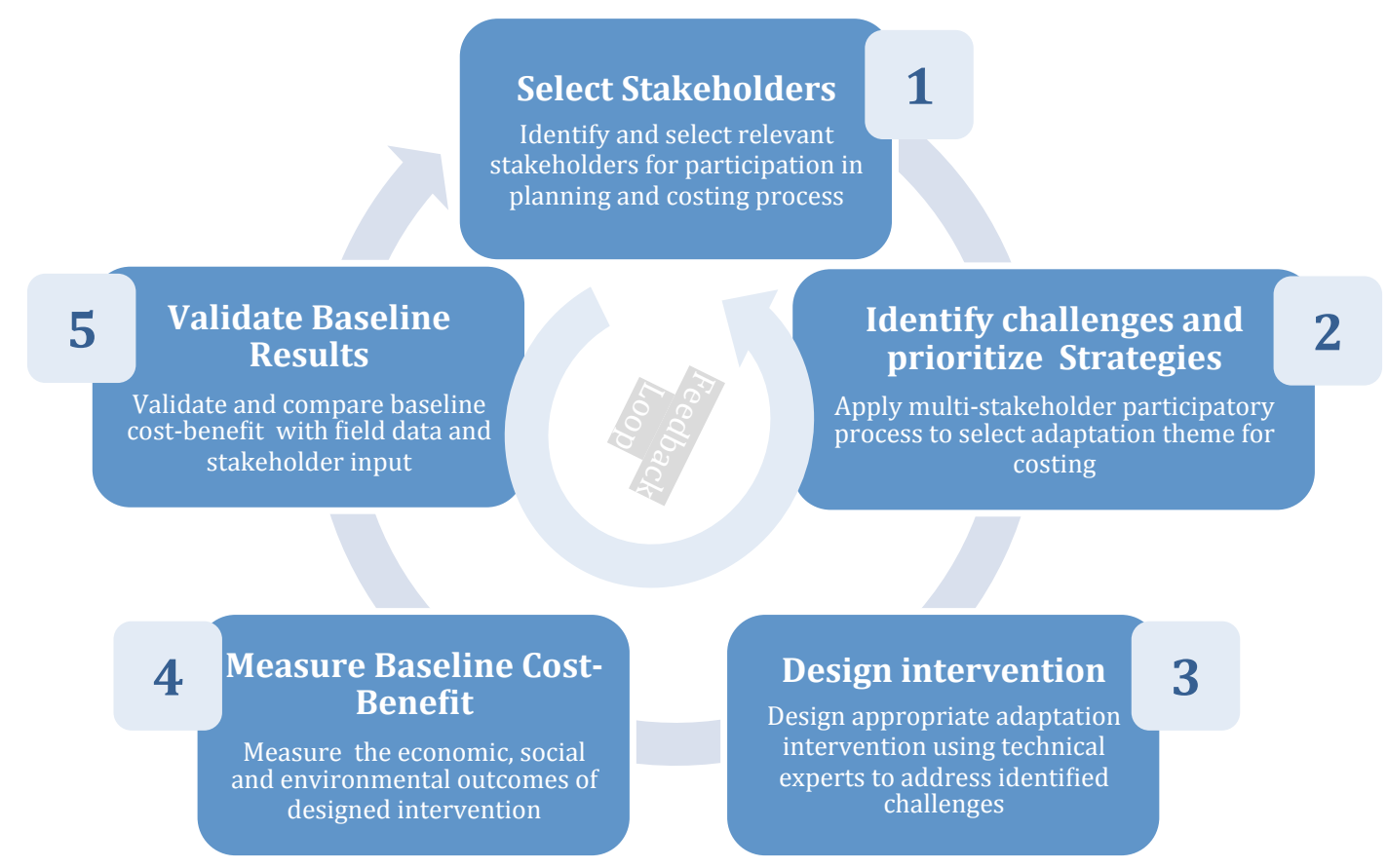

Figure 1 - PSROI Five Steps Analysis

Step 1 - Select stakeholders. The PSROI analysis begins with selection of representative stakeholders to participate in the conception of an appropriate adaptation theme. Stakeholders are defined as actors that are directly or indirectly affected by the proposed adaptation process (Green, 2002). Stakeholder selection is typically undertaken by the PSROI project leader and, depending on who initiates the PSROI analysis, this can be a community member, researcher, private sector or public sector representative. Stakeholder selection is an imperfect and recursive process and will vary based on the location and nature of the analysis. It is important to have a transparent and unbiased selection criterion that is clearly communicated to the participants of the analysis. By allowing people to self-select and recommend others, using snowballing techniques (Biernacki and Waldorf, 1981, Goodman, 1961) allows for the process to be more inclusive and transparent while also respecting the right of people not to participate. The underlying premise for a multi-stakeholder approach is that issues are generally connected and no one person or organization can address a challenge alone. 
Many individuals, groups, organizations are involved in developing and executing any plan (Bryson, 2004). A detailed stakeholder analysis is undertaken to identify relevant and broad representation that can meaningfully contribute to the adaptation selection and valuation process, before the workshop starts. Stakeholders are included if they have information that cannot be gained otherwise, or if their participation is necessary to ensure successful implementation of the initiatives but are not included when their involvement is impractical, unnecessary, or imprudent (Thomas, 1995). The process is designed to gain necessary information, build political acceptance, and address some of the questions about legitimacy, representation and credibility of stakeholders from the perspective of users of the action plans.

Actor mapping exercises triangulated with transect walks, are used to identify key informants (or gatekeepers) and ensure that members of different social or marginalized groups within the location are included in the analysis. Particular emphasis is placed on achieving equal gender representation, but considerations of age, economic status, education, geographic distribution within the location of analysis, profession and other locally relevant categories also play a part in determining the selection of stakeholder.

Step 2 - Identify challenges and prioritize strategies. This step begins with a participatory diagnostic workshop comprising the selected stakeholders from step 1 . The workshop is designed together with local stakeholders to ensure function and cultural appropriateness of any specific activities. The workshop maps local values and norms, identifies key environmental challenges, risks and historical responses, explores visions of the future and identifies currently available assets and resources using Appreciative Inquiry (Copperrider and Srivastva, 1987). It then selects adaptation themes with the highest potential to achieve the community's desired vision of their future. Plans are developed with communities by using the 'backcasting' technique of working 
backwards from future visions to present strengths, capacities and assets, in order to determine what actions would be required to reach that future vision (Robinson, 1982). According to Robinson (1982, p.337), "the major distinguishing characteristic of backcasting analysis is a concern, not with likely... futures, but with how desirable futures can be attained". The participatory techniques used in this step may be supplemented with other established Participatory Rural Appraisal techniques and methods to enable local communities to define the sort of action they require (McGee, 2002, Chambers, 1992).

The final output from this step is a democratically selected, usually by voting, prioritized, adaptation theme(s) or action(s) that is based on local strengths and offers a tangible solution to the environmental challenges identified.

Step 3 - Design intervention. The diagnostic workshop in step 2 produces broad adaptation plans that contain certain adaptation actions demanded by the stakeholders. These plans are developed further into specific adaptation interventions that incorporate technical design characteristics obtained by consultation with local partners and experts, to facilitate costing and validation analysis in steps 4 and 5. It is in this technical design phase that any intervention is tested for its adaptive appropriateness, i.e. its capacity to address future climatic challenges, by using implicit or multiple climate scenarios (IPCC, 2007) and reduction of climatic risks. Steps 2 and 3, involving strategy prioritization and intervention design, provide ownership to the users over the adaptation intervention and, as Chambers (2002) argues, implies a commitment to equity and empowerment that should improve implementation and facilitate a more transparent costing process. 
Step 4 - Measure baseline cost-benefits. In this step, a baseline (market potential) PSROI ratio is calculated for the economic, social and environmental impacts of the designed intervention using secondary data from academic literature, industry standards, experts and key informants. Evidence is collected for the potential outcomes of the intervention that are monetized using market values or financial proxies. All benefits are added and the costs subtracted to calculate the NPV of the intervention over a determined period and then compared with the initial costs (investment). This baseline PSROI ratio serves as a traditional desk-based PSROI.

Choosing an appropriate discount rate to calculate the NPV in PSROI is a hotly debated subject as it can change the valuation of the interventions significantly (Weitzman, 2007, Nordhaus, 2007, Stern, 2007). For projects with long timeframes as in the case of climate change, higher discount rates (as used in commercial valuations) can undervalue the needs of future generations. Stern (2007) argues for a low discount rate as ethically justifiable to balance future damage costs against current costs. Choosing a time frame for the project is also important as it affects the overall valuation of the intervention. The time frame may be based on the life span of the intervention or a fixed period of time determined by the stakeholders. However, forecasting results beyond a certain time increases the risk of error thus limiting the validity of the results. Discount rates and time periods are subjective and directly affect the valuations, therefore careful consideration and analysis is required to select the most appropriate variables, based on local considerations. This is challenging for local stakeholders and hence may require more expert assistance. A sensitivity analysis, at various discount rates, may ameliorate the subjectivity by providing the range of effect produced by different rates on the PSROI ratio. 
Multiple stakeholders contribute to the intervention design, planning and implementation, therefore the costs and benefits are segregated, based on the respective contributions of the stakeholders. This promotes transparency and equitable sharing of costs and benefits by stakeholders.

Step 5 - Validate Baseline Results. The final step of the PSROI framework captures the perceptions and values of local stakeholders involved in the analysis and compares these with the baseline PSROI. The comparison is intended as a process of validation and discovery. Semi-structured interviews are conducted with a representative sample of the study stakeholders, including participants and non-participants of the diagnostic workshop in step 2. These interviews aim to validate the step 4 findings, intervention analysis and assumptions included in the baseline PSROI. Discovery of additional benefits, and alternate interpretations of technical or market assumptions by the community are also included in this step of the PSROI analysis. The PSROI ratio is then recalculated from primary field data and compared with the baseline PSROI ratio. Where stakeholder and market perceptions diverge, key insights into measures of success and assumptions of community value are revealed.

PSROI framework is a recursive process that may require several iterations to match the needs of the stakeholders with an appropriate intervention, and vice versa. This process may lead to the identification of a single or several equally competing interventions. The analysis can be performed on a single prioritized intervention or a combination of interventions, subject to time and cost constraints. The prioritized list of interventions is in itself a valuable outcome of the PSROI process that can serve as a qualified wish list for the community to link with other current and future projects. 
The PSROI ratio used for planning purposes requires estimates of costs and benefits yet to be realised over the lifetime of a project, rather than for monitoring and evaluation. There are always unexpected consequences of any intervention and it is only by involving as many diverse stakeholders as practically possible in analysing the planning process that we can minimise our blind spots. PSROI overcomes this challenge by involving end-users in exploring the different interventions (external and internal) in their own context. The planning PSROI can ultimately serve as a valuable benchmark for post implementation analysis.

\section{Findings from Application of PSROI in Western Kenya}

\subsection{Western Kenya Pilot Site}

This region of East Africa presented a suitable choice of location to pilot the PSROI framework because the region is highly vulnerable to climate variability and change (Thornton et al., 2006) and particularly for the numerous local development challenges faced by smallholder agricultural populations (Thomas and Twyman, 2005).

The PSROI pilot site of Kochiel Village in Kombewa District, Kisumu, Western Kenya is a small subsistence farming community near the Lake Victoria Basin with approximately 43 homesteads. Kochiel has a humid to sub-humid climate with mean annual rainfall between $600 \mathrm{~mm}-1600 \mathrm{~mm}$ and a reliability of $60 \%$. The Luo community predominates in this area. Typical farms are 1-10 acres in size and farmers primarily depend on the farms for their livelihood using their own labour. The major resources are land and labour. The farmer groups have limited access to modern farming technology. The main economic activities include: small-scale farming, processing agricultural products, small-scale commodity trade, and livestock rearing. The people are very poor 
and the area shows serious environmental degradation with little tree cover, major soil erosion and poor soil fertility (Wiebke et al., 2011).

\subsection{PSROI Framework Application}

The PSROI pilot started with a preliminary scoping exercise at Kochiel to define the scope of analysis and select stakeholders, in consultation with the local leader and community members. A three-day multi-stakeholder diagnostic workshop was held to select the theme for climate adaptation with 41 attendees from a wide range of local stakeholders, which included farmers, self-employed, teachers, students, public officials, NGOs representatives, widows, women, youth, and group leaders. This was followed by 35 semi-structured interviews at community level in 23 homesteads and 7 exploratory and experts interviews with chosen representatives of stakeholders who occupied key positions in government agencies, NGOs, and the farming community. These were selected using stratification and snowball sampling techniques.

The participants ranked inadequate farming knowledge as the biggest environmental challenge in the diagnostic workshop. Participant's established formal connections through workshop exercises, between various environmental challenges and identified responses to counter such challenges from their own experience, a key feature of strength-based approach. Instead of focusing solely on immediate solutions to a challenge, the participants recognized that a holistic cause-effect analysis was required. For example, one group ranked insufficient water as a key environmental issue and linked it to increased run-off and a lower water table, the result of deforestation. Another participant shared how he had cost-effectively dug a rainwater storage pond the previous season for use in times of dry spells. Backcasting exercises were conducted on several selected goals to identify implementation pathways to link the community's future visions with their existing resources. The workshop concluded with the participants 
voting among five shortlisted adaptation options for the agroforestry theme for PSROI analysis because it addressed their main challenges of soil degradation, water run off and income diversification.

With assistance from experts in agroforestry supported by technical literature that included Sustainable Agriculture and Land Management (SALM) menu developed by the World Bank (2010b), Agro-silviculture (intercropping trees) was selected for the intervention design. This is the practice of growing selected species of trees on the cropland in a mixed spatial (scattered) system. While no particular intervention may be able to address all the challenges identified by the community, the aim is to select a technically sound intervention that addresses the key challenges and includes managing the threat of future climate change and is suitable for local implementation. Although, for the purpose of the pilot, a single intervention design was chosen, there is nothing to preclude a multi-intervention approach.

Using expert agroforestry industry data, case studies, academic literature, and direct information from agroforestry specialists, the designed agroforestry intervention based on one-acre standard farm projected baseline benefits of KES 389,657 (Kenyan Shillings - 1USD = KES 85 - 2013) against initial input costs of KES 8,195 over a 20-year project lifespan at a discount rate of $15 \%$ (based on the average bank borrowing rate). This translated into baseline PSROI ratio of KES 47 net benefits for each KES 1 investment (ratio of 47:1). This high baseline PSROI ratio presents an attractive case, to the stakeholders, on paper, for implementing the agroforestry intervention.

Table 1 and Figure 2 highlight the sensitivity of the PSROI ratio to different discount rates. Increasing the discount rate from $5 \%$ to $35 \%$ reduces the PSROI ratio from KES 126 to KES 13. 


\begin{tabular}{|c|c|c|}
\hline Discount Rate & Net Present Value & PSROI Ratio \\
\hline $5.0 \%$ & $1,032,407$ & 126 \\
\hline $7.5 \%$ & 781,917 & 95 \\
\hline $10.0 \%$ & 604,180 & 74 \\
\hline $15.0 \%$ & 381,462 & 47 \\
\hline $20.0 \%$ & 257,440 & 31 \\
\hline $25.0 \%$ & 183,846 & 22 \\
\hline $30.0 \%$ & 137,557 & 17 \\
\hline $35.0 \%$ & 106,870 & 13 \\
\hline
\end{tabular}

Table 1: Baseline PSROI Ratio Sensitivity Analysis at Different Discount Rates

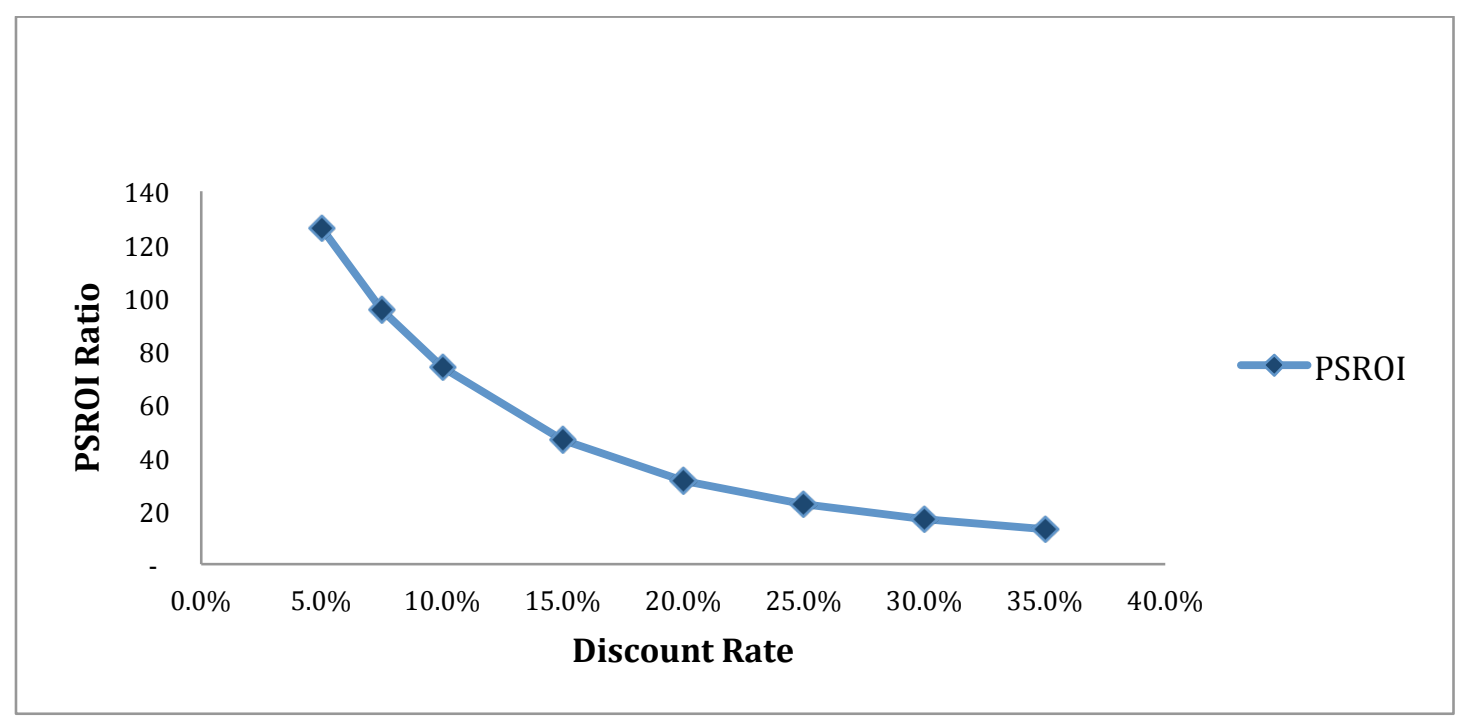

Figure 2: Baseline PSROI Ratio Sensitivity Analysis at Different Discount Rates

The baseline benefits breakup calculation in Figure 3 shows contributions from sale of tree timber $(38 \%)$, savings in the cost of animal fodder $(25 \%)$ and firewood $(15 \%)$, while improved crop yield (19\%) and health (3\%) contribute towards the balance of benefits. Contribution from carbon credit payments to farmers for agroforestry projects under the current World Bank carbon project in the area is negligible at less than $0.1 \%$ of the total benefits. The baseline cost breakup in Figure 3 shows that labor cost, i.e. the time spent by the farmers in planting and maintaining the trees, is the main expense (56\%), followed by cost of farmer training in agroforestry $(19 \%)$, seedlings $(12 \%)$ and tools $(12 \%) .80 \%$ of the total cost is borne directly by the farmers, while $20 \%$ is borne by support organizations such as development NGOs. Land is considered a sunken cost 
as it is assumed to be already available to farmers without further investment, while water is rain fed at zero cost.

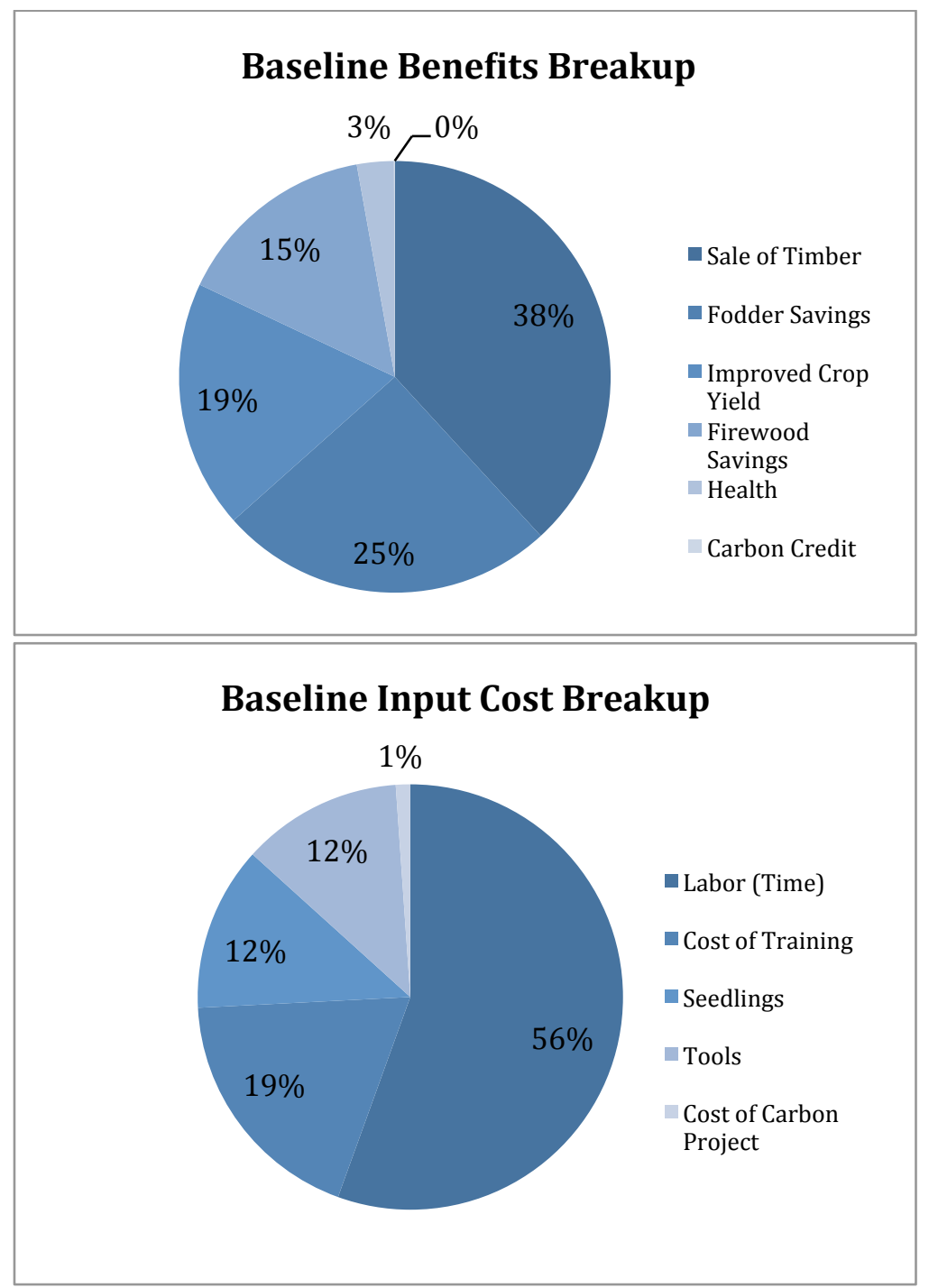

Figure 3: Baseline Benefits and Input Costs Breakup

The final step in the PSROI analysis is a field validation of the selected intervention. Because the population of Kochiel Village is relatively small, stratification of the population and snowball sampling techniques were considered sufficient for selecting 35 interviewees from 23 of the 42 homesteads, which gave a 55\% coverage. Semistructured interviews were conducted and standardized open-ended questions were asked so that the respondents' answers could be compared (Patton, 1990). The interviews were conducted at homesteads to triangulate their responses with observation of their circumstances. Benefits and costs were only included in this field validated 
PSROI if they were specifically identified by more than half the 23 homesteads interviewed.

A majority of the interviewees identified labor and seeds as the main input costs required for the agroforestry intervention. There was a much wider range of responses about the perceived benefits with all interviewees identifying the short-term benefits of firewood and improved fodder availability, but only 3 (16\%) of interviewees identifying improved crop yield. One explanation for this observation may be the difficulty of segregating the benefits between objectives that are deeply interconnected: for example, combating soil erosion and improved crop yield. Consequently, crop yield benefits were not included in the field validated PSROI. Several interviewees identified non-monetary environmental benefits of agroforestry including shade value of trees $(60 \%)$, positive impact on microclimate $(50 \%)$ and aesthetic value of trees $(20 \%)$. These benefits, though important for the community, could not be included in the PSROI ratio calculation for lack of credible financial proxies, but were identified as non-quantifiable benefits. Overall, a mixed approach was used for identifying the impact measures. For example a simple average was used to work out the labor hours, whereas benefit from timber sale was calculated using the mode of the answers as not all interviewees identified this benefit.

Table 2 and Figure 4 show the difference between the baseline and field assumptions and the impact on the PSROI ratio of the field assumptions. When community estimate of the key input costs and benefits are included, the PSROI ratio drops by over $70 \%$ from the baseline ratio of KES 47 to KES 13 for each KES 1 investment. Projected net benefits decrease by $45 \%$ to KES 210,869 while initial input costs increase by $126 \%$ to KES 18,495 over the baseline estimates. In other words, the community had a much lower perceived value of the intervention than the projected baseline value. 
The main drop in the baseline PSROI ratio of 24 , results from the difference in labor costs estimates. The community identified seven hours per week labor for planting and tending seedlings against the baseline assumption of two hours per week, as according to the community tree seedlings require more care in early stages especially in unpredictable rains. Similarly the community assumed 15 years maturity period for trees against the baseline assumption of 10 years due to lack of knowledge about the recommended tree varieties, resulting in drop in baseline PSROI ratio by 4 . A majority of the community was not aware of the improved crop yield benefits from agroforestry and the baseline calculation did not account for the potential income from fruit trees identified by the community. The baseline PSROI ratio, as a result of these factors, decreased from KES 47 to KES 13 for each 1 KES investment.

\begin{tabular}{|c|c|c|c|c|}
\hline $\begin{array}{l}\text { Key Community } \\
\text { Insights }\end{array}$ & $\begin{array}{l}\text { Baseline } \\
\text { Assumption }\end{array}$ & $\begin{array}{l}\text { Field Based } \\
\text { Assumption }\end{array}$ & $\begin{array}{l}\text { Impact on } \\
\text { Baseline } \\
\text { PSROI Ratio } \\
\text { (KES 47:1) }\end{array}$ & $\begin{array}{l}\text { Field } \\
\text { Validated } \\
\text { PSROI Ratio }\end{array}$ \\
\hline $\begin{array}{l}\text { Increase in labor } \\
\text { time on maintenance } \\
\text { of trees }\end{array}$ & 2hrs per week & 7hrs per week & -24 & 23 \\
\hline Increase in tools cost & KES 1,000 & KES 3,500 & -2 & 21 \\
\hline $\begin{array}{l}\text { Delay in benefits of } \\
\text { sale of timber - } \\
\text { Maturity period }\end{array}$ & 10 years & 15 years & -5 & 16 \\
\hline $\begin{array}{l}\text { Non-identification } \\
\text { of improved crop } \\
\text { yield from } \\
\text { agroforestry }\end{array}$ & 0.5 ton per acre & Zero & -4 & 12 \\
\hline $\begin{array}{l}\text { Identification of } \\
\text { income from fruit } \\
\text { trees }\end{array}$ & Nil & $\begin{array}{l}\text { KES } 200 \text { per } \\
\text { month }\end{array}$ & +1 & 13 \\
\hline
\end{tabular}

Table 2- Impact of Field Based Assumptions (Community Insights) on the Baseline PSROI Ratio 


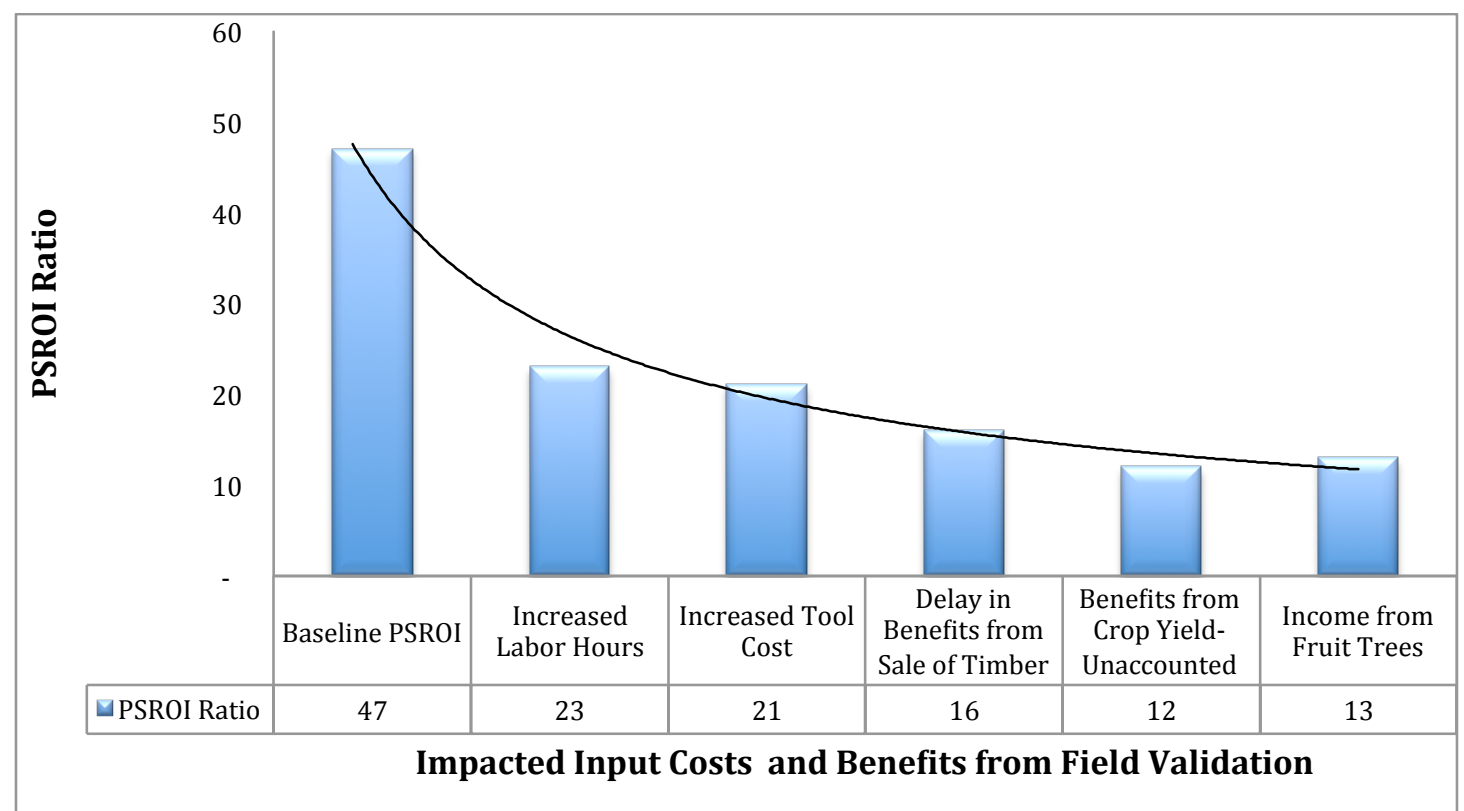

Figure 4 - Impact of Field Based Assumptions (Community Insights) on the Baseline PSROI Ratio. Baseline PSROI Ratio Calculated at $\mathbf{1 5 \%}$ Discount Rate

The purpose of the comparing the baseline valuation and community-based valuation is not to choose one result over the other based on the accuracy of data, but to quantify and recognize the differences between the two and so to inform decision-making and ensure more responsive planning and design process. The structural and methodological insights gained from these differences are analysed in detail in the discussion section.

\subsection{Limitations in PSROI Pilot Application}

A well-designed, participatory methodology is key to the success of the PSROI framework, hence special attention was given to develop robust methods for its application. Despite this, there are limitations as with all methodologies. Significantly, the pilot application focused on a single adaptation theme of agroforestry. Having many themes and analyzing their co-benefits would enrich the analysis. A small study population also limits the depth of any analysis and the opportunity to explore more diverse responses. 


\section{Discussion}

The focus of this paper, highlighted in the methodology section, is to evaluate the PSROI framework and not to assess the suitability of the selected intervention. Results from the pilot help evaluate PSROI as a robust and scalable framework and are discussed in this section.

\subsection{Community Participation Aids the Design of Adaptation Interventions}

Development practices already encourage discussion with communities to increase efficiency, effectiveness and sustainability (Mikkelsen, 2005). PSROI solicits active community participation in the process, particularly at two key steps of the framework: Step 2 - Identify challenges and prioritize strategies; and Step 5 - Validate baseline results. A low community valuation warns of either a mismatch of the intervention with local needs and/or poor perceptions of the intervention's potential costs and benefits to the community. The $70 \%$ difference between the baseline and community validated PSROI ratios in this pilot signals serious divergence in the value and attractiveness of the intervention between external experts and the local community (see Table 2). Tackling these challenges and misperceptions early would improve the success of implementation. On the other hand a high community valuation could identify unforeseen benefits to project designers, such as income from fruit trees identified by locals and signal potential opportunities for private and public sector funding. In the field site, for example, community willingness to pay for seedlings, storage and distribution presented a potential economic opportunity for agricultural enterprises.

\subsection{Information Gaps can Skew Valuations}

While farmers identified key inputs of the recommended agroforestry intervention with high accuracy (100\% in the case of labour, seedlings and water inputs), they were less 
successful in identifying potential benefits. It is harder to visualize the benefits of complex interventions, such as intercropping trees when its effect on crop production is indirect and delayed. This makes the intervention appear less attractive to the farmers and may result in low uptake. Farmers failed to account for improved crop yields in their decision-making process because of a lack of information. This produced a decrease in the PSROI ratio of KES 4 or $9 \%$ (See Table 2), making the agroforestry intervention much less attractive than its potential value. Alongside a lack of information, inaccurate information is also critically important that requires a targeted solution. Although 83\% (19) of the farmers correctly recognized the benefit from sale of timber, they believed the mode age of the tree maturity to be 15 years, as opposed to 10 years specified in the baseline. This delayed benefit decreased the PSROI ratio by a further KES 5 or $11 \%$ (See Table 2).

Critical examination of differences in baseline and field validated PSROI ratios is imperative for any successful uptake of planned projects, as it is easy for the project developers to confuse information gaps for lack of resources or enthusiasm from the farmers. Analysis of other agroforestry initiatives in Africa show that training is crucial for the adoption of new methods and/or scaling up of successful initiatives (Salami et al., 2010, Noordin et al., 2001). Therefore training and raising awareness are important components that should be considered at the project planning and intervention design stage to ensure effective implementation.

\subsection{The Need for Long-Term Thinking}

It is difficult for vulnerable communities to visualize long-term benefits, given their immediate and pressing needs and the high opportunity costs of delayed benefits. As a result, they place low value on distant benefits (hence implicitly using a higher discount rate), making long-term interventions less attractive. One 40-year-old male farmer ( $\mathrm{M}$. 
Kwacha 2011, Personal Communication, 10 July) in Kochiel summed up this sentiment despite recognizing the long-term commercial benefits of trees: "If you have a tree and you need to feed the family, you (have to prematurely) cut it and sell it." Table 1 and Figure 2 show that the baseline PSROI ratio deceases by almost $50 \%$ for a $10 \%$ increase in the discount rate, highlighting the sensitivity of the ratio to higher discount rates.

Understanding the specific needs of stakeholders, a key step of PSROI, helps match interventions to their needs, rather than offering generic solutions. Tailored project design that meets various pressing needs, while improving long-term adaptive capacity, is more likely to succeed. For example, planting fast-maturing trees for animal fodder and firewood alongside slow-maturing timber trees may protect the latter from premature cutting.

\subsection{Cost Estimation- Willingness to Pay}

An important factor observed during the community decision-making process was the timing and amount of the input costs in relation to farm income. Input costs of the agroforestry intervention, such as labor, tools and seedlings, were immediate, which posed a significant burden on the farmers' income. Hanemann et al. (1991) explains that for many people, willingness to pay is likely to be very limited when their incomes are very low. We observed this directly when we asked how much a farmer was willing to pay for hiring help and how much compensation he was willing to accept. The answer was invariably a much lower willingness to pay. The farmers projected labor costs to be much higher than the baseline estimate because tree seedlings, based on local experience, require more care in early stages especially when rains are unpredictable. This increased the estimated input cost twofold and so reduced the PSROI ratio by $50 \%$ (see Table 2), which acted as strong deterrent for a successful uptake. Agencies need to 
recognize the local realties for meeting perceived costs of any intervention during the design and implementation phase.

\subsection{Understand the Diverse Pressures on Farmers}

The PSROI faces a challenge common to all costing frameworks: capturing the different risk preferences of individuals within a community. This limitation can create serious misconceptions among different shareholders when measuring the success of an intervention. Government officials in Kenya blamed the village's low crop yield on farmer apathy, while farmers explained that they were not prepared to risk using costly commercial fertilizers to increase yields, in case the rains were late. Research indicates that, without credit or crop insurance, farmers will not necessarily grow the most profitable crops (Hazell et al., 1986). They will focus instead on resilient, low-risk, lowyield crops to ensure survival, even if many of their crops fail. For the PSROI analysis to be effective, it needs to be supported by other cultural, political, institutional and viability analysis.

\subsection{Developing Valuation Proxies}

The PSROI valuation process must identify outcomes and monetize these using financial proxies. For example, improved crop yield due to tree planting was monetized using the market price of maize multiplied by the yield increase. Unfortunately, not all outcomes and proxies are so easily identifiable. Measuring the shade value of trees, identified by $60 \%$ of interviewees, is far more challenging even with non-monetary valuation (NMV) methods. Indeed the very notion of what constitutes shade can vary culturally, as seen in Dove's (2003) analysis of diverse models and mismatched valuation of tree shade between Pakistani farmers and forestry officials. NMV methods remain specious in the eyes of decision makers, who often view these results reluctantly. This means that rigor must be applied in determining these values, adding time and cost to the analysis. Given 
these limitations, PSROI avoids applying the most contested NMV strategies of contingent valuations (Diamond and Hausman, 1994, Hausman, 1993) and employs strategies like benefit transfer (transferring available information from previously completed studies in different locations and/or contexts). Social and environmental impacts, for which proxies cannot be determined, are not included in the PSROI calculation but classified in the analysis with anecdotal evidence to recognize their qualitative value. The growing popularity of SROI in the social sector can be partly attributed to research that develops proxy databases, which allow organizations to capture hard to measure outcomes in the valuation. In order to promote PSROI as a mainstream planning and costing tool for climate change adaptation, complementary research is needed to develop and populate an environmental financial proxy database.

\subsection{Influence of Stakeholders}

The stakeholder perspective of outcomes is central to the PSROI framework. An iterative process is used to capture the broadest impact of the selected intervention by balancing the scope of the intervention and the views of relevant stakeholders. In this process, the influence of a dominant stakeholder could impact the scope of the system perversely and skew selection of to an intervention that benefits particular stakeholders disproportionately. The Carbon Finance Project (CFP) of The World Bank (2011) was identified as an additional stakeholder for inclusion in the PSROI analysis during the interview process. The PSROI calculation reflects that, while the carbon credit payments under the CFP offer negligible contribution of less than $0.1 \%$ to the overall benefits of the agroforestry intervention (see Figure 3), the project has a strong influence on the local community through recommendation under the SALM menu (World Bank, 2010b), in partnership with a dominant local NGO. This is not to say that interventions promoted under SALM do not offer benefits to the community. There is, however, a 
greater risk of bias towards excluding non-carbon-focused projects that may potentially offer higher and more obvious benefits to the local community. PSROI allows for more targeted analysis to rationalize influence of stakeholders by matching their participation with their contributions.

\subsection{Scalability and Transferability}

Distinct growing seasons, soil composition, management practices and cultural norms limit widespread adoption of standardized adaptation strategies. These challenges are compounded by uncertainties about how these unique climatic zones will change, which increases the risk of maladaptation to climate change if standard interventions are adopted widely. The PSROI framework reflects these important considerations and consequently discourages the transfer of adaptation strategies, or their perceived costs and benefits, directly to other communities, without local analysis. The same holds true for extrapolating an intervention across the national landscape.

For example a linear extrapolation of the PSROI ratio of KES 47:1 would generate KES 47 million net benefits against an investment of KES 1 million. This calculation is too simplistic because it ignores the economies and diseconomies of scale and assumes asymmetry in decision making. As discussed earlier, there was a strong agroforestry NGO presence in Kochiel due to a well-funded soil carbon initiative in the area. This resulted in sound agroforestry knowledge and the capacity to produce seedlings that would not necessarily exist in other communities, even in those close to Kochiel. Scaling the findings in such a way could seriously misinform decision makers and divert funds from other measures more appropriate to the surrounding communities. As in any financial decision-making, caution is needed in using the PSROI framework exclusively, without making realistic location-specific adjustments. 


\section{Conclusion}

Adapting to climate change is as much about empowering communities through building capacity to cope with change as it is about finding solutions to protect against the negative consequences of climate change. Participation is at the heart of the PSROI process, since it attempts a valuation from the stakeholder's point of view. Despite this, assigning monetary value to any action carries the risk of comparing actions with others that do not appear comparable. A government can justify a decision to build a new road in a village over providing clean water, based on the relative net monetary benefits of the two projects. Whether the comparison is skewed because of lack of rigor in identifying the less researched, and perhaps intangible, benefits of clean water, or simply a valuation methodology issue, is debatable.

PSROI is a promising analytical framework that offers users tools and methods to plan and cost interventions for adapting to climate change that reflect local realities. PSROI empowers local stakeholders to conduct their own analysis, and valuations of interventions by using their strengths as basis. In this way, stakeholders can build their own capacity to adapt in the face of climate change while generating valuable local data to inform global and national decision-making. Although PSROI generates quantitative data and information, it is far more than simply a costing tool. Incorporating local knowledge in desk-based planning and costing can reveal valuable insights into what local stakeholders think about the planned interventions. Infact real and important insights accrue from understanding and analyzing these differences in valuations.

While active participation does not guarantee that local stakeholders always choose the most beneficial intervention or adopt the most effective adaptation path, PSROI helps to 
minimize the subjectivity and influence of external agents by passing the onus of decision-making to local stakeholders. It is hoped that by encouraging such local decision-making, the likelihood of long term up take and sustainability of adaptive projects will improve. PSROI is in its infancy and would therefore benefit greatly from further practical field application and study in various climatic zones and sectors in order to improve its use as a planning, implementation and analysis tool for stakeholders.

\section{Acknowledgement:}

This paper would not have been possible without the project and financial support of CGIAR Research Program on Climate Change Agriculture and Food Security (CCAFS) and Climate and Development Knowledge Network (CDKN). We would also like to thank Caitlin Cornor-Dolloff for her valuable insights in shaping the PSROI framework and Michael Kettlewell, Nora Steurer and Sally Kingsborough for their in-depth editorial review of the paper.

\section{References}

ACKOFF, R. L. 1974. Redesigning the future: a systems approach to societal problems, New York, Wiley.

ADGER, W. N., HUQ, S., BROWN, K., CONWAY, D. \& HULME, M. 2003. Adaptation to climate change in the developing world. Progress in Development Studies, 3, 179-195.

APPLEFORD, G. 2013. Exploring strengths-based approaches in the design of a family planning project in Kenya. Development in Practice, 23, 145-150. 
BATEMAN, I. J. \& WILLIS, K. G. 2001. Valuing environmental preferences: theory and practice of the contingent valuation method in the US, EU, and developing countries, Oxford, Oxford University Press.

BIERNACKI, P. \& WALDORF, D. 1981. Snowball sampling: problems and techniques of chain referral sampling. Sociological Methods \& Research, 10, 141-163.

BOYLE, D. 2000. The tyranny of numbers: why counting can't make us happy, New York, HarperCollins.

BROWN, T. 2009. Change by design, New York, HarperCollins.

BRYSON, J. M. 2004. What to do when stakeholders matter: stakeholder identification and analysis techniques. Public Management Review, 6, 21-53.

CHAMBERS, R. 1992. Rural apprasial: rapid, relaxed and participatory. Discussion Paper 311. Brighton: Institute of Development Studies

CHAMBERS, R. 1994. Paradigm shifts and the practice of participatory research and development. Working Paper 2. Brighton: Institute of Development Studies

CHAMBERS, R. 2002. Participatory workshops: a sourcebook of 21 sets of ideas and activities, UK and USA, Earthscan.

CHAMBWERA, M. \& STAGE, J. 2010. Climate change adaptation in developing countries: issues and perspectives for economic analysis.

http://pubs.iied.org/15517IIED.html. London: International Institute for Environment and Development (IIED).

COOKE, B. \& KOTHARI, U. 2001. Participation: The new tyranny?, London and New York, Zed Books Ltd.

COPPERRIDER, D. L. \& SRIVASTVA, S. 1987. Appreciative Inquiry in Organizational Life. In: WOODMAN, W. P. A. R. (ed.) Research in Organisational Change and Development. Greenwich: JAI Press Inc.

DIAMOND, P. A. \& HAUSMAN, J. A. 1994. Contingent valuation: is some number better than no number? The Journal of Economic Perspectives, 8, 45-64.

DOVE, M. R. 2003. Bitter shade: throwing light on politics and ecology in contemporary Pakistan. Human Organization, 62, 229-241.

ECONOMICS OF CLIMATE ADAPTATION WORKING GROUP 2009. Shaping ClimateResilient Development: a framework for decision-making. http://mckinseyonsociety.com/downloads/reports/EconomicDevelopment/ECA_Shaping_Climate Resilent_Development.pdf. London: ClimateWorks Foundation, Global Environment Facility, European Commission, McKinsey \& Company, The Rockefeller Foundation, Standard Chartered Bank and Swiss Re.

GAVENTA, J. 2004. Towards participatory governance: assessing the transformative possibilities. In: HICKY, S. \& MOHAN, G. (eds.) Participation: From tyranny to transformation. Zed Books Ltd.

GOODMAN, L. A. 1961. Snowball sampling. The Institute of Mathematical Statistics, 32, 148170. 
GRANOVETTER, M. S. 1973. The strength of weak ties. American Journal of Sociology, 78, 1360-1380.

GREEN, M. 2002. Development Theory and Practice. In: KOTHARI, U. \& MINOGUE, M. (eds.) Social Development: Issues and Approaches. Critical Perspectives. Palgrave.

HANEMANN, M., LOOMIS, J. \& KANNINEN, B. 1991. Statistical efficiency of doublebounded dichotomous choice contingent valuation. American Journal of Agricultural Economics, 73, 1255-1263.

HANLEY, N. 1992. Are there environmental limits to cost benefit analysis? Environmental and Resource Economics, 2, 33-59.

HAUSMAN, J. 1993. Contingent valuation: a critical assessment, Amsterdam, North-Holland.

HAZELL, P. B., POMAREDA, C. \& VALDÉS, A. 1986. Crop insurance for agricultural development: issues and experrience. Baltimore and London: The John Hopkins University Press.

HELFGOTT, A. 2011. Resilience, adaptation and development. MSc Lecture Series. Oxford: University of Oxford.

HUQ, S. \& REID, H. 2004. Mainstreaming Adaptation in Development. IDS Bulletin, 35, 15-21.

IPCC 2007. Climate change 2007: synthesis report. contribution of working groups I, II and III to the fourth assessment report of the Intergovernmental Panel on Climate Change. In: [CORE WRITING TEAM, P., R.K AND REISINGER, A. \& (EDS.)] (eds.) http://www.ipcc.ch/publications_and_data/publications_ipcc_fourth_assess ment_report_synthesis_report.htm

Geneva, Switzerland: IPCC.

IPCC 2014. Summary for policymakers. Climate change 2014: impacts, adaptation, and vulnerability. Part A: global and sectoral aspects. Contribution of working group II to the fifth assessment report of the Intergovernmental Panel on Climate Change. In: FIELD, C. B., V.R. BARROS, D.J. DOKKEN, K.J. MACH, M.D. MASTRANDREA, T.E. BILIR, M. CHATTERJEE, K.L. EBI, Y.O. ESTRADA, R.C. GENOVA, B. GIRMA, E.S. KISSEL, A.N. LEVY, S. MACCRACKEN, P.R. MASTRANDREA, AND L.L. WHITE (ed.) http://ipccwg2.gov/AR5/images/uploads/WG2AR5_SPM_FINAL.pdf. Cambridge, United Kingdom and New York, NY, USA: IPCC.

IYIANI, C., BINNS, T. \& SHANNON, P. 2011. HIV/AIDS prevention: building on community strengths in Ajegunle, Lagos. Development in Practice, 21, 1080-1093.

KHWAJA, A. I. 2004. Is increasing community participation always a good thing? Journal of the European Economic Association, 2, 427-436.

KING, G., KEOHANE, R. O. \& VERBA, S. 1994. Designing social inquiry: scientific inference in qualitative research, Princeton, New Jersey, Princeton University Press.

LINGANE, A. \& OLSEN, S. 2004. Guidelines for social return on investment. California Management Review, 46, 116-135.

LUNDUKA, R., BEZABIH, M. \& CHAUDHURY, A. 2012. Stakeholder-focused cost benefit analysis in the water sector: A synthesis report. 
http://pubs.iied.org/pdfs/16523IIED.pdf? London: International Institute for Environment and Development (IIED).

MALPEZZI, S. 2008. Hedonic Pricing Models: A Selective and Applied Review. In:

O'SUllivan, T. \& GIBB, K. (eds.) Housing Economics and Public Policy. Oxford, UK: Blackwell Science Ltd.

MCGEE, R. 2002. Participating in development. In: KOTHARI, U. \& MINOGUE, M. (eds.) Development theory and practice: Critical perspectives. Palgrave.

MCGRAY, H., HAMMILL, A., BRADLEY, R., SCHIPPER, E. L. \& PARRY, J.-E. 2007. Weathering the storm: Options for framing adaptation and development. http://www.wri.org/publication/weathering-storm. Washington, DC: World Resources Institute.

MIKKELSEN, B. 2005. Methods for development work and research: a new guide for practitioners, SAGE Publications Pvt. Limited.

MITCHELL, R. C. \& CARSON, R. T. 1989. Using surveys to value public goods: the contingent valuation method, New York, Resource for the Future.

MOSSE, D. 2004. Is good policy unimplementable? Reflections on the ethnography of aid policy and practice. Development and change, 35, 639-671.

MUNASINGHE, M. 2003. Analysing the nexus of sustainable development and climate change: an overview. http://www.oecd.org/env/cc/2510070.pdf. Paris: OECD Development and Climate Change Project.

NELSON, N. \& WRIGHT, S. 1995. Power and participatory development: theory and practice, London, Intermediate Technology Publications Ltd (ITP).

NICHOLLS, J., LAWLOR, E., NEITZERT, E. \& GOODSPEED, T. 2012. A guide to Social Return on Investment.

http://www.thesroinetwork.org/component/docman/cat_view/29-thesroi-guide/223-the-guide-in-english-2012-edition?Itemid=362. London: The SROI Network.

NOORDIN, Q., NIANG, A., JAMA, B. \& NYASIMI, M. 2001. Scaling up adoption and impact of agroforestry technologies: experiences from western Kenya. Development in Practice, 11, 509-523.

NORDHAUS, W. D. 2007. A review of the" Stern Review on the Economics of Climate Change". Journal of Economic Literature, 45, 686-702.

NYONG, A., ADESINA, F. \& ELASHA, B. O. 2007. The value of indigenous knowledge in climate change mitigation and adaptation strategies in the African Sahel. Mitigation and Adaptation Strategies for Global Change, 12, 787-797.

OECD 2009. Integrating climate change adaptation into development co-operation - policy guidance. http://www.oecd.org/dac/43652123.pdf. Paris: OECD.

OKA, T. 2003. Effectiveness and limitations of cost-benefit analysis in policy appraisal. Government Auditing Review, 10, 17-28.

OMURA, M. 2004. Cost-benefit analysis revisited: is it a useful tool for sustainable development? Kobe University Economic Review, 50, 43-58. 
ORUM, A. M., FEAGIN, J. R. \& SJOBERG, G. 1991. A case for the case study, USA, University of North Carolina Press.

OSTROM, E. 2010. A multi-scale approach to coping with climate change and other collective action problems. Solutions, 1, 27-36.

PARRY, M., ARNELL, N., BERRY, P., DODMAN, D., FANKHAUSER, S., HOPE, C., KOVATS, S., NICHOLLS, R., SATTERTHWAITE, D., TIFFIN, R. \& WHEELER, T. 2009. Assessing the costs of adaptation to climate change: a review of the UNFCCC and other recent estimates, London, International Institute for Environment and Development and Grantham Institute for Climate Change.

PATTON, M. Q. 1990. Qualitative evaluation and research methods (2nd ed.), Touand Oaks, CA, SAGE Publications Inc.

PREST, A. R. \& TURVEY, R. 1965. Cost-benefit analysis: a survey. The Economic Journal, 75, 683-735.

RAHNEMA, M. 1992. Participation. In: SACHS, W. (ed.) The Development Dictionary. London: Zed Books Ltd.

RITTEL, H. \& WEBBER, M. 1973. Dilemmas in a general theory of planning. Policy Sciences, $4,155-169$.

ROBINSON, J. B. 1982. Energy backcasting A proposed method of policy analysis. Energy policy, 10, 337-344.

SALAMI, A., KAMARA, A. B. \& BRIXIOVA, Z. 2010. Smallholder agriculture in East Africa: trends, constraints and opportunities, Working Paper Series N10. http://www.afdb.org/fileadmin/uploads/afdb/Documents/Publications/W ORKING 105 PDF d.pdf. Tunis, Tunisia: African Development Bank Group.

SALEEBEY, D. 1996. The strengths perspective in social work practice: extensions and cautions. Social Work, 41, 296-305.

SILVERMAN, D. 2013. Doing qualitative research: A practical handbook, London, SAGE Publications Ltd.

SMIT, B. \& PILIFOSOVA, O. 2003. From adaptation to adaptive capacity and vulnerability reduction. In: SMITH, J. B., KLEIN, R. J. T. \& HUQ, S. (eds.) Climate change, adaptive capacity and development.

SMIT, B. \& WANDEL, J. 2006. Adaptation, adaptive capacity and vulnerability. Global Environmental Change, 16, 282-292.

SMITH, B., BURTON, I., KLEIN, R. J. \& WANDEL, J. 2000. An anatomy of adaptation to climate change and variability. Climatic Change, 45, 223-251.

SMITHERS, J. \& SMIT, B. 1997. Human adaptation to climatic variability and change. Global Environmental Change, 7, 129-146.

STERN, N. H. 2007. The economics of climate change: The Stern Review, Cambridge, Cambridge University Press. 
SUMERNET. 2013. Participatory Social Return on Investment (PSROI): Greater Mekong Basin Climate Change Adaptation Planning and Costing Project. http://www.bit.ly/1qHDOZg [Online]. Sumernet. [Accessed June 10, 2014]

TELLIS, W. 1997. Application of a case study methodology. The qualitative report [On-line serial], 3(3). http://www.nova.edu/ssss/QR/QR3-3/tellis2.html, 3, 1-17.

THOMAS, D. S. \& TWYMAN, C. 2005. Equity and justice in climate change adaptation amongst natural-resource-dependent societies. Global Environmental Change, 15, 115 124.

THOMAS, J. C. 1995. Public participation in public decisions: new skills and strategies for public managers, San Francisco, Jossey-Bass.

THORNTON, P. K., JONES, P. G., OWIYO, T., KRUSKA, R., HERRERO, M., KRISTJANSON, P., NOTENBAERT, A., BEKELE, N. \& OMOLO, A. 2006. Mapping climate vulnerability and poverty in Africa. http://bit.ly/1jcwXWI. Nairobi: ILRI.

THORNTON, T. F. \& MANASFI, N. 2010. Adaptation—genuine and spurious: demystifying adaptation processes in relation to climate change. Environment and Society: Advances in Research, 1, 132-155.

ULRICH, W. 1987. Critical heuristics of social systems design. European Journal of Operational Research, 31, 276-283.

UNDP 2007. Human Development Report- fighting climate change: human solidarity in a divided world. .

http://hdr.undp.org/sites/default/files/reports/268/hdr_20072008_en_co mplete.pdf. New York: United Nations Development Programme.

UNFCCC 2007. Investment and Financial Flows to Address Climate Change. . http://unfccc.int/resource/docs/publications/financial_flows.pdf. Bonn: UNFCCC Change Secretariat.

WEITZMAN, M. L. 2007. A review of the Stern Review on the economics of climate change. Journal of Economic Literature, 45, 703-724.

WIEBKE, F., PATTI, K., PHILIP, T. \& KIPLIMO., J. 2011. Initial sites in the CCAFS Regions: East Africa, West Africa and Indo-Gangetic plains.

http://ccafs.cgiar.org/sites/default/files/assets/docs/ccafs_siteportfolio_v2 .pdf. Copenhagen, Denmark: CGIAR Research Program Climate Change, Agriculture and Food Security (CCAFS).

WORLD BANK 2010a. Economics of adaptation to climate change - Synthesis report. . http://documents.worldbank.org/curated/en/2010/01/16436675/econo mics-adaptation-climate-change-synthesis-report. Washington D.C.: World Bank.

WORLD BANK 2010b. Sustainable Agriculture Land Management practices (SALM). http://www.v-c-s.org/methodologies/VM0017. Carbon Finance Unit- The World Bank.

WORLD BANK. 2011. Kenya: Agricultural Carbon Project. http://www.worldbank.org/projects/P107798/kenya-agricultural-carbon- 
project?lang=en [Online]. Carbon Finance Unit - The World Bank. [Accessed May 6, 2014] 